\title{
Assessing the reliability and validity of comprehensive score for financial toxicity (COST) among radiation oncology patients in India: a cross-sectional pilot study
}

\author{
Mukhtar Ahmad Dar ${ }^{1}$, Richa Chauhan ${ }^{2}$, Krishna Kumar Sharma ${ }^{1}$, Vinita Trivedi ${ }^{2}$, Sameer Dhingra ${ }^{1}$ and Krishna Murti ${ }^{1}$ \\ ${ }^{1}$ Department of Pharmacy Practice, National Institute of Pharmaceutical Education and Research (NIPER), Hajipur 844102, Bihar, India \\ ${ }^{2}$ Department of Radiotherapy, Mahavir Cancer Sansthan and Research Centre (MCSRC), Patna 801505, Bihar, India
}

\begin{abstract}
Background: Besides physical toxicity, cancer care imposes significant financial distress referred to as financial toxicity (FT). FT has become a growing concern among cancer patients. Researchers have associated FT among cancer patients with clinical outcomes like mortality, poor quality of life and non-adherence. Currently, no reliable tools are available for assessing FT among cancer patients in India. The aim of this pilot study was to test the reliability and validity of the Comprehensive Score for Financial Toxicity (COST) questionnaire among patients undergoing radiotherapy in India.
\end{abstract}

Material and methods: This cross-sectional pilot study was conducted among head and neck cancer patients on follow-up in radiation oncology department. The reliability of COST measure was assessed using Cronbach's $a$. The underlying construct of COST was verified by Exploratory Factor Analysis (EFA). EFA was performed using parallel analysis technique.

Results: Based on inclusion and exclusion criteria, the COST questionnaire was administered to 29 patients using the interview method after written informed consent. The COST measure demonstrated excellent reliability with Cronbach's a of 0.92. A Kaiser-MeyerOlkin of 0.87 verified the sample adequacy and a $p$-value of $<0.001$ on Bartlett's sphericity test indicated that the strength of the correlation between 11 COST items was good to perform the EFA. Parallel analysis technique identified one factor on scree plot with eigenvalue of 6.21 explaining $56.5 \%$ of the variance by non-rotated solution. All the factor loadings in one factor model were $>0.3$ (range 0.35-0.97). The factor loadings indicated that the underlying construct can be considered as one factor domain as intended by the original COST development study. However, Chi-square goodness of fit test revealed the one factor model did not adequately depict the data. However, the results were consistent with the construct obtained in the original scale development study.

Conclusion: This pilot study demonstrated excellent reliability of COST for measuring FT among radiation oncology patients. Further studies are warranted to study the clinical implications of FT in the Indian population for making better strategies and policies to ease the financial burden on cancer patients.

Keywords: financial toxicity, COST, reliability, exploratory factor analysis
Correspondence to: Mukhtar Ahmad Dar Email: darmukthar55@gmail.com

ecancer 2021, 15:1219

https://doi.org/10.3332/ecancer.2021.1219

Published: 09/04/2021

Received: 22/01/2021

Publication costs for this article were supported by ecancer (UK Charity number 1176307).

Copyright: (C) the authors; licensee ecancermedicalscience. This is an Open Access article distributed under the terms of the Creative Commons Attribution License (http:// creativecommons.org/licenses/by/3.0), which permits unrestricted use, distribution, and reproduction in any medium, provided the original work is properly cited. 


\section{Introduction}

The burden of cancer is increasing at an alarming rate in India. GLOBOCAN 2018 has estimated over 1.1 million incident cancer cases and 0.78 million cancer deaths in India in 2018 [1]. In addition to the physical toxicity, cancer care imposes a significant financial burden on patients. With the development of new drugs, imaging, radiation and surgical techniques, the cost of cancer care has escalated in past few decades. Oncology patients often suffer the economic consequences of cancer treatment including high out-of-pocket (OOP) expenses (direct and indirect costs) and loss of income. The adverse effects of financial hardships experienced by cancer patients because of cancer care are termed as financial toxicity (FT) [2]. Zafar et al [2] concluded that FT is analogous to physical toxicity among cancer patients.

A systematic review by Altice et al [3] reported that 47\%-49\% of cancer survivors experienced some form of the financial burden and $12 \%$ $62 \%$ of the patients reported being in debt because of cancer treatment. Researchers have linked FT with several clinically relevant outcomes like health-related quality of life (HRQOL) indicating negative effects of FT on HRQOL [4, 5]. Ramsey et al [6, 7] have reported association of FT with early mortality and greater risk for bankruptcy. While several other studies have reported association of FT with treatment compliance [8], medication non-adherence [9, 10] and forgoing treatment [11].

Studies among Indian cancer patients have reported catastrophic expenditures among 76.5\% of the patients [12]. In India, 40\% of cancer patients use borrowings, sale of assets as coping strategies to pay for cancer treatment [13]. A study conducted at All India Institute of Medical Sciences (AIIMS), New Delhi reported that about 59\% of the cancer care was spent on transportation, food and lodging during radiotherapy (RT) treatment [14]. An OOP expenses study conducted in north India reported the total mean expenditure was ten times the per capita income and indirect costs were significantly higher than direct costs [15].

India is a lower-middle income country with large population and extremely low health insurance coverage. Majority of the medical expenses are OOP expenses. Currently, there are no validated tools for assessment of subjective FT among cancer patients in Indian healthcare system. To the authors' knowledge, this is the first study in India assessing subjective FT and the authors aim to test the reliability and validity of Comprehensive Score for Financial Toxicity (COST) for measuring FT among radiation oncology patients.

\section{Materials and methods}

\section{Study design and participants}

This cross-sectional pilot study was conducted at Mahavir Cancer Sansthan and Research Centre (MCSRC), Patna, India. The study was approved by Institutional Ethics Committee. Patients aged $\geq 18$ years with a diagnosis of head and neck cancer who have completed the radiation therapy either as stand-alone or part of multimodal treatment regimen were eligible for participation in this study. Those who were not able to understand Hindi or English language or unable to give informed consent were excluded. Consecutive patients attending radiation oncology out-patient department (OPD) at MCSRC were approached to participate in this study. Patients willing to give informed consent were enrolled for participation in this study. All the financial burden related questions were directed towards radiation therapy only. Based on the literature search, a sample size of 30 patients was selected for this study.

\section{Data collection}

Socio-demographic and clinical characteristics were collected from the patient's record file in a pre-designed case record form. Responses to COST items were recorded via face-to-face interview during follow-up OPD visits. The questions were properly explained one by one to the participants in a language they understand in presence of a family member/caregiver and the responses were recorded accordingly. 


\section{COST administration and scoring guidelines}

The COST-Functional Assessment of Chronic illness Therapy (FACIT) was developed by De Souza and colleagues as a patient reported outcome measure for assessment of FT among cancer patients in the USA. The COST development study reported an excellent internal consistency (Cronbach's a of 0.92), test-retest reliability and correlation with HRQOL [16].

The COST measure has already been validated for assessment of FT in different cancer care settings across the USA including advanced solid tumours [17], radiation oncology [18], gynaecologic oncology [19], multiple myeloma [20], lung cancer [21] and surgery [22]. COST measure has also been translated and adapted for use in different healthcare systems by other countries including Japan [23], Italy [24] and Brazil [25].

A proper permission and licensing agreement was provided by the original developer via FACIT.org to use COST-FACIT (Version 2) in this study. Although COST is a patient reported outcome measure designed for self-administration, however, FACIT administration and scoring guidelines allow for the face-to-face or telephonic interview-based administration [26].

The original COST-FACIT (Version 1) was developed on a 5-point Likert scale (0-4) with 11 items. The COST-FACIT (Version 2) is a measure of 12 items (Supplementary Figure 1). The 12 items on COST have been officially coded sequentially from FT1 to FT12 and in this study COST items are presented as codes only. According to FACIT scoring guidelines, the additional item - FT12 is a summary item and does not add to the total score of the questionnaire, i.e. item 12 must be excluded. Items 2, 3, 4, 5, 8, 9 and 10 are reverse scored. The responses vary from 0 (not at all), 1 (a little bit), 2 (somewhat), 3 (quite a bit) and 4 (very much). The total cost score ranges from 0 to 44 and lower score corresponds to higher FT. The total COST score has been subdivided into four groups indicating different grades of FT. Thus, COST score $\geq 26$ indicates no impact (Grade 0), 14-25 means mild impact (Grade 1), 1-13 means moderate impact (Grade 2) and a score of 0 means high impact (Grade 3).

\section{Statistical analysis}

The individual responses to the COST questionnaire were entered into SPSS (Version 20) for analysis. The reliability or internal consistency of COST indicating the degree to which the individual items comprising the scale measure the underlying construct was assessed by the Cronbach's $a$. Coefficients $>0.9$ were considered excellent. Spearman's correlation was performed to demonstrate the correlation between the scale items. Kaiser-Meyer-Olkin (KMO) test to measure sampling adequacy, Bartlett's sphericity test was performed to test the significance of all the correlations within the correlation matrix. Exploratory Factor Analysis (EFA) was performed for factor identification based on the $\mathrm{KMO}$ and Bartlett's sphericity test $[27,28]$.

\section{Results}

Based on inclusion and exclusion criteria, the COST questionnaire was administered to 29 patients via interview method for this pilot study. A total of 30 head and neck cancer patients on follow-up after RT were approached for participation in this study. One patient was excluded as the patient was unable to give consent and was not accompanied by a family member/caretaker. The socio-demographic and clinical characteristics of the participants are presented in Table 1 . The mean age of the participants was $49.5 \pm 16.8$ (range 20-74) and $82.8 \%$ were male.

\section{Reliability analysis}

The 11 items for COST measure had a Cronbach's a of 0.92 ( $95 \%$ confidence interval) indicating excellent reliability. No increase in Cronbach's a values was observed if any of the individual items were deleted from the scale as indicated in Table 2.

Spearman's correlation test was performed for all the items in the COST as shown in Table 3. Cohen's standard was used to evaluate the strength of the relationships, where coefficients between 0.10 and 0.29 represent a small effect size, coefficients between 0.30 and 0.49 represent a moderate effect size and coefficients above 0.50 indicate a large effect size [29]. 
Table 1. Sociodemographic and clinical characteristics of study participants $(N=29)$.

\begin{tabular}{|c|c|c|c|}
\hline Characteristics & $N(\%)$ & Characteristics & $N(\%)$ \\
\hline Sex & & Primary cancer site & \\
\hline Male & $24(82.8)$ & Tongue & $5(17.2)$ \\
\hline Female & $5(17.2)$ & Gingival buccal sulcus & $5(17.2)$ \\
\hline Age group & & Buccal mucosa & $4(13.7)$ \\
\hline less than 50 & $14(48.3)$ & Supraglottic larynx & $3(10.30$ \\
\hline $50-59$ & $4(13.8)$ & Hypopharynx & $2(6.9)$ \\
\hline 60 and above & $11(37.9)$ & Parotid & $2(6.9)$ \\
\hline Education level & & Thyroid & $1(3.5)$ \\
\hline Not educated & $10(34.5)$ & Floor of mouth & $1(3.5)$ \\
\hline Primary level & $14(48.3)$ & Para nasal sinus & $1(3.5)$ \\
\hline Secondary level & $3(10.3)$ & Central arch lower alveolus & $1(3.5)$ \\
\hline Graduate and above & $2(6.9)$ & Oropharynx & $1(3.5)$ \\
\hline Occupation & & Rt. tonsil & $1(3.5)$ \\
\hline Employed & $4(13.8)$ & Sub mandibular gland & $1(3.5)$ \\
\hline Unemployed & $3(10.3)$ & Lower lip & $1(3.5)$ \\
\hline Labour work & $10(34.3)$ & Disease extent & \\
\hline Farming & $3(10.3)$ & Metastatic & $1(3.5)$ \\
\hline Homemaker & $2(6.9)$ & Non-metastatic & $28(96.5)$ \\
\hline Others & $7(24.1)$ & Treatment modality & \\
\hline Household size & & Radiotherapy (RT) & $5(17.2)$ \\
\hline 1-5 members & $12(41.4)$ & RT + surgery (S) & $14(48.3)$ \\
\hline 6-10 members & $15(51.7)$ & RT + chemotherapy (CT) & $6(20.7)$ \\
\hline More than 10 members & $2(6.9)$ & $\mathrm{RT}+\mathrm{CT}+\mathrm{S}$ & $4(13.8)$ \\
\hline Marital status & & Treatment intent & \\
\hline Married & $28(96.5)$ & Definitive & $15(51.7)$ \\
\hline Unmarried & $1(3.5)$ & Adjuvant & $11(38.0)$ \\
\hline Annual household income (Rs.) & & Palliative & $3(10.3)$ \\
\hline$\leq 50,000$ & $17(58.6)$ & Time since RT & \\
\hline $50,000-100,000$ & $11(37.9)$ & 6 months or less & $7(24.1)$ \\
\hline $100,000-200,000$ & $1(3.5)$ & 6 months to 12 months & $10(34.5)$ \\
\hline Residence & & 12 months to 24 months & $6(20.7)$ \\
\hline Rural & $29(100)$ & More than 24 months & $6(20.7)$ \\
\hline Urban & 0 & Health insurance & \\
\hline Current employment status & & Yes & $2(6.9)$ \\
\hline Stopped working & $18(62.1)$ & No & 27 (93.1) \\
\hline No change in work & $5(17.2)$ & & \\
\hline Reduction in working hours & $6(20.7)$ & & \\
\hline
\end{tabular}


Table 2. Descriptive and reliability indices for 11 items of COST measure.

\begin{tabular}{|l|c|c|c|}
\hline \multicolumn{1}{|c|}{ COST items } & Mean & Std. deviation & Cronbach's alpha if item deleted \\
\hline FT1 & 0.38 & 0.62 & 0.917 \\
\hline FT2 & 0.69 & 0.66 & 0.926 \\
\hline FT3 & 1.0 & 1.22 & 0.906 \\
\hline FT4 & 0.76 & 0.95 & 0.927 \\
\hline FT5 & 1.66 & 1.47 & 0.919 \\
\hline FT6 & 0.69 & 1.11 & 0.909 \\
\hline FT7 & 1.52 & 1.40 & 0.917 \\
\hline FT8 & 1.34 & 1.49 & 0.903 \\
\hline FT9 & 1.17 & 1.49 & 0.906 \\
\hline FT10 & 0.93 & 1.03 & 0.908 \\
\hline FT11 & 0.66 & 1.01 & 0.904 \\
\hline
\end{tabular}

Table 3. Spearman's correlation for 11 item COST measure $(N=29)$.

\begin{tabular}{|c|c|c|c|c|c|c|c|c|c|c|c|c|}
\hline \multicolumn{2}{|c|}{ COST items } & FT1 & FT2 & FT3 & FT4 & FT5 & FT6 & FT7 & FT8 & FT9 & FT10 & FT11 \\
\hline \multirow{2}{*}{ FT1 } & $r_{\mathrm{s}}$ & & 0.31 & $0.68^{a}$ & 0.17 & 0.25 & $0.69^{b}$ & $0.47^{a}$ & $0.61^{a}$ & $0.38^{b}$ & $0.52^{a}$ & $0.69^{a}$ \\
\hline & $p$ & & 0.10 & 0.00 & 0.38 & 0.19 & 0.00 & 0.01 & 0.00 & 0.04 & 0.00 & 0.00 \\
\hline \multirow{2}{*}{ FT2 } & $r_{\mathrm{s}}$ & 0.31 & & $0.41^{b}$ & 0.30 & $0 \cdot 13$ & 0.27 & 0.17 & 0.31 & 0.10 & 0.27 & 0.37 \\
\hline & $p$ & 0.10 & & 0.03 & 0.11 & 0.52 & 0.16 & 0.38 & 0.10 & 0.60 & 0.16 & 0.05 \\
\hline \multirow{2}{*}{ FT3 } & $r_{\mathrm{s}}$ & $0.68^{a}$ & $0.41^{b}$ & & 0.28 & $0.52^{\mathrm{a}}$ & $0.87^{a}$ & $0.59^{a}$ & $0.79^{a}$ & $0.57^{a}$ & $0.58^{a}$ & $0.78^{a}$ \\
\hline & $p$ & 0.00 & 0.03 & & $0 \cdot 15$ & 0.00 & 0.00 & 0.00 & 0.00 & 0.00 & 0.00 & 0.00 \\
\hline \multirow{2}{*}{ FT4 } & $r_{\mathrm{s}}$ & 0.17 & 0.30 & 0.28 & & 0.27 & 0.20 & 0.00 & 0.17 & 0.13 & 0.27 & 0.25 \\
\hline & $p$ & 0.38 & 0.11 & 0.15 & & 0.16 & 0.29 & 1.00 & 0.39 & 0.50 & 0.15 & 0.20 \\
\hline \multirow{2}{*}{ FT5 } & $r_{s}$ & 0.25 & 0.13 & $0.52^{\mathrm{a}}$ & 0.27 & & $0.45^{b}$ & 0.34 & $0.56^{a}$ & $0.79^{a}$ & $0.53^{a}$ & $0.51^{a}$ \\
\hline & $p$ & 0.19 & 0.52 & 0.00 & 0.16 & & 0.01 & 0.07 & 0.00 & 0.00 & 0.00 & 0.00 \\
\hline \multirow{2}{*}{ FT6 } & $r_{\mathrm{s}}$ & $0.69^{b}$ & 0.27 & $0.87^{a}$ & 0.20 & $0.45^{b}$ & & $0.62^{a}$ & $0.69^{a}$ & $0.54^{a}$ & $0.58^{a}$ & $0.75^{a}$ \\
\hline & $p$ & 0.00 & 0.16 & 0.00 & 0.29 & 0.01 & & 0.00 & 0.00 & 0.00 & 0.00 & 0.00 \\
\hline \multirow{2}{*}{ FT7 } & $r_{s}$ & $0.47^{a}$ & 0.17 & $0.59^{a}$ & 0.00 & 0.34 & $0.62^{\mathrm{a}}$ & & $0.64^{a}$ & $0.59^{a}$ & $0.51^{a}$ & $0.62^{a}$ \\
\hline & $p$ & 0.01 & 0.38 & 0.00 & 1.00 & 0.07 & 0.00 & & 0.00 & 0.00 & 0.01 & 0.00 \\
\hline \multirow{2}{*}{ FT8 } & $r_{\mathrm{s}}$ & $0.61^{a}$ & 0.31 & $0.79^{a}$ & 0.17 & $0.56^{a}$ & $0.69^{a}$ & $0.643^{a}$ & & $0.77^{a}$ & $0.71^{a}$ & $0.87^{a}$ \\
\hline & $p$ & 0.00 & 0.10 & 0.00 & 0.39 & 0.00 & 0.00 & 0.00 & & 0.00 & 0.00 & 0.00 \\
\hline \multirow{2}{*}{ FT9 } & $r_{s}$ & $0.38^{b}$ & 0.10 & $0.57^{a}$ & 0.13 & $0.79^{a}$ & $0.54^{a}$ & $0.59^{a}$ & $0.77^{a}$ & & $0.71^{a}$ & $0.69^{a}$ \\
\hline & $p$ & 0.04 & 0.60 & 0.00 & 0.50 & 0.00 & 0.00 & 0.00 & 0.00 & & 0.00 & 0.00 \\
\hline \multirow{2}{*}{ FT10 } & $r_{\mathrm{s}}$ & $0.52^{\mathrm{a}}$ & 0.27 & $0.58^{a}$ & 0.27 & $0.53^{a}$ & $0.58^{a}$ & $0.58^{a}$ & $0.71^{\mathrm{a}}$ & $0.71^{a}$ & & $0.83^{a}$ \\
\hline & $p$ & 0.00 & 0.16 & 0.00 & 0.15 & 0.00 & 0.00 & 0.01 & 0.00 & 0.00 & & 0.00 \\
\hline \multirow{2}{*}{ FT11 } & $r_{s}$ & $0.69^{a}$ & 0.37 & $0.78^{a}$ & 0.25 & $0.51^{a}$ & $0.75^{a}$ & $0.75^{a}$ & $0.87^{a}$ & $0.69^{a}$ & $0.83^{a}$ & \\
\hline & $p$ & 0.00 & 0.05 & 0.00 & 0.20 & 0.00 & 0.00 & 0.00 & 0.00 & 0.00 & 0.00 & \\
\hline
\end{tabular}

${ }^{\mathrm{a}}$ Correlation is significant at the 0.01 level (2-tailed)

${ }^{\mathrm{b}}$ Correlation is significant at the 0.05 level (2-tailed)

Spearman's rho $\left(r_{s}\right)$ values are reported 
A significant positive correlation was observed between FT1 and FT3 $\left(r_{s}=0.68, p<0.001,95 \% \mathrm{Cl}(0.41,0.84)\right)$. The correlation coefficient between FT1 and FT3 was 0.68 , indicating a large effect size. This correlation indicates that as FT1 increases, FT3 tends to increase. A similar large effect size was observed in 30 other correlation combinations as depicted by $r_{s}$ values in Table 3 . A significant positive correlation was observed between four correlation combinations indicating a moderate effect size. A total of 70/110 correlation combinations were significant based on $p$-value indicating $63.6 \%$ significant correlation.

\section{Exploratory factor analysis}

Normality of the data was verified by multivariate normality. The squared Mahalanobis distances were calculated for the data and plotted against the quantiles of a Chi-square distribution. In the scatterplot, the solid line represents the theoretical quantiles of a normal distribution. Normality can be assumed if the points form a relatively straight line. The scatterplot for normality is presented in Figure 1.

EFA was performed after KMO and Bartlett's test verified the sample adequacy and significant correlation between 11 COST items. Results of KMO and Bartlett's test are presented in Table 4. A KMO $<0.8$ verifies the sample adequacy and $p$-value of $<0.001$ in Bartlett's test indicates the strength of the relationship between COST items was good and it is possible to perform EFA on this data.

Parallel analysis was chosen for electing number of factors to retain. For this selection method, uncorrelated normal variables are randomly generated that parallel the data in the number of variables and sample size. Next, the observed eigenvalues were extracted from the correlation matrix with the diagonal of the matrix being replaced by each variable's squared multiple correlations to estimate each variable's communality. These observed eigenvalues are then compared to the eigenvalues of the randomly generated variables. The actual eigenvalues that have a higher value than its randomly generated counterpart are retained for interpretation [30]. Figure 2 shows the scree plot comparing the observed and random eigenvalues. Scree plot shows that there was only one factor that had a greater eigenvalue than its randomly generated counterpart. As a result, one factor with eigenvalue of 6.21 explaining $56.5 \%$ of the variance by non-rotated solution was identified in factor analysis.

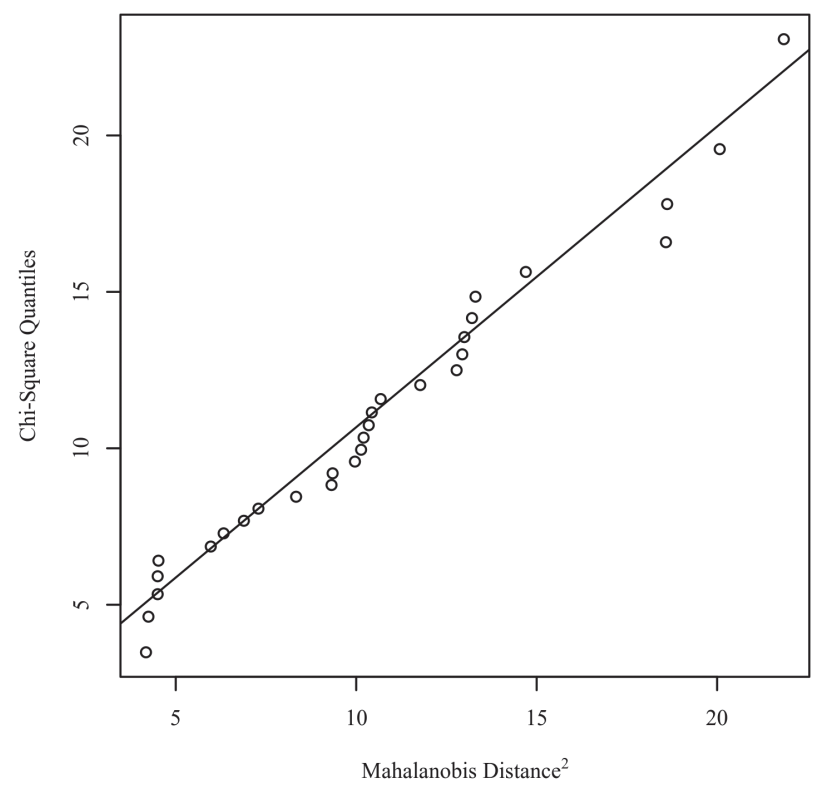

Figure 1. Mahalanobis distance scatterplot testing multivariate normality. 
Table 4. $\mathrm{KMO}$ and Bartlett's test $(\mathrm{N}=29)$.

\begin{tabular}{|l|l|c|}
\hline \multicolumn{2}{|l|}{ KMO Measure of sampling adequacy } & 0.865 \\
\hline Bartlett's test of sphericity & Approx. $\chi 2$ & 254.04 \\
\cline { 2 - 3 } & $d f$ & 55 \\
\cline { 2 - 3 } & Sig. $(p)$ & $0.000^{a}$ \\
\hline
\end{tabular}

${ }^{a} p$-value significance level $<0.001$

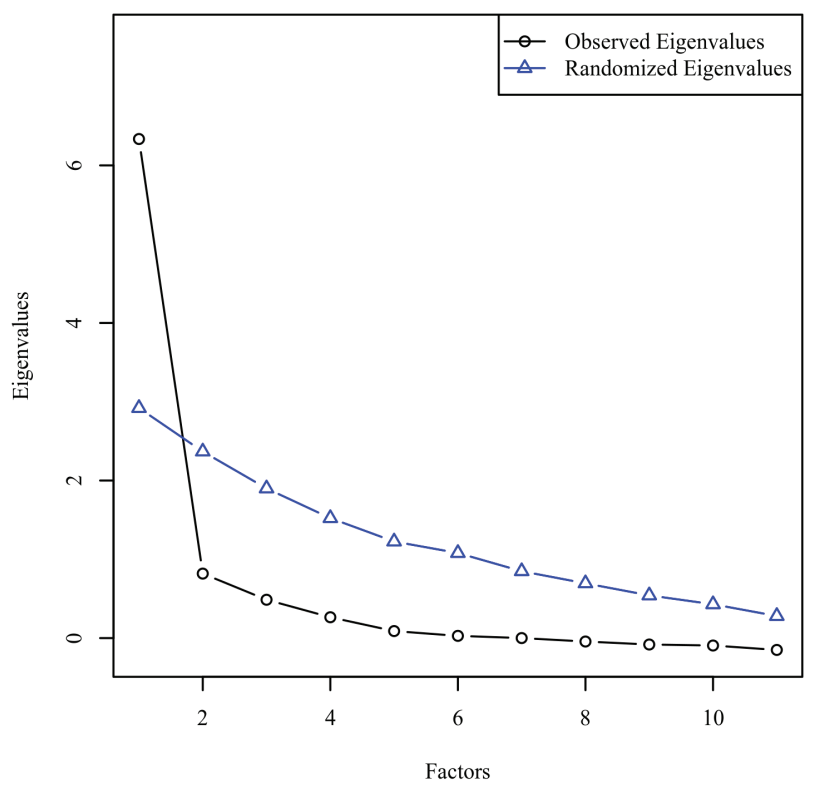

Figure 2. Scree plot comparing observed and random eigenvalues for parallel analysis.

The factor loadings were interpreted by taking the absolute value of each loading and implementing the criterion by Tabachnick et al recommending that values $>0.32$ should be the minimum threshold used to identify significant factor loadings [31]. Six items (FT1, FT3, FT6, FT8, FT9, FT10 and FT11) on COST measure showed excellent loadings for Factor 1, one item (FT7) showed very good loading for Factor 1, one item (FT5) had good loading for Factor 1 and two items (FT2, FT3) showed only acceptable factor loadings of >0.3 for Factor 1 as shown in Table 5. A Chi-square goodness of fit test was conducted to determine if the one-factor model fits the data perfectly based on an alpha value of $0.05, \chi^{2}(44)=60.82, p=0.047$ indicating that the one-factor model did not adequately depict the data due to low sample size.

Financial toxicity measures

The mean COST score for 29 patients included in this study was $10.8 \pm 9.6$ (range 0-33) and 62\% patients suffered moderate impact (Grade 2) while $7 \%$ experienced high impact (Grade 3) FT. Figure 3 shows the distribution of patients by grading COST score using COST-FACIT scoring guidelines.

Patient-oncologist cost communication behaviour and cost coping strategies were also assessed during interview process (Table 6). Almost $90 \%$ of the patients discussed their financial situation and affordability of radiation therapy and associated tests to their radiation oncologist. Multiple strategies were employed by patients to pay for cancer care, $86 \%$ applied for government financial aid available for people below poverty line, $55 \%$ used their savings and $69 \%$ borrowed money from social nets. Due to cancer, $62 \%$ reported stopped working and about $21 \%$ reported reduction in working hours. 
Table 5. Factor loadings of 11 COST items from EFA $(N=29)$.

\begin{tabular}{|l|l|}
\hline COST items & Factor loading 1 \\
\hline $\begin{array}{l}\text { FT1 (I know that I have enough money in savings, retirement or assets to cover the costs of my } \\
\text { treatment) }\end{array}$ & 0.74 \\
\hline FT2 (My OOP medical expenses are more than I thought they would be) & 0.37 \\
\hline FT3 (I worry about the financial problems I will have in the future as a result of my illness or treatment) & 0.86 \\
\hline FT4 (I feel I have no choice about the amount of money I spend on care) & 0.35 \\
\hline FT5 (I am frustrated that I cannot work or contribute as much as I usually do) & 0.59 \\
\hline FT6 (I am satisfied with my current financial situation) & 0.82 \\
\hline FT7 (I am able to meet my monthly expenses) & 0.69 \\
\hline FT8 (I feel financially stressed) & 0.92 \\
\hline FT9 (I am concerned about keeping my job and income, including work at home) & 0.80 \\
\hline FT10 (My cancer or treatment has reduced my satisfaction with my present financial situation) & 0.87 \\
\hline FT11 (I feel in control of my financial situation) & 0.97 \\
\hline
\end{tabular}

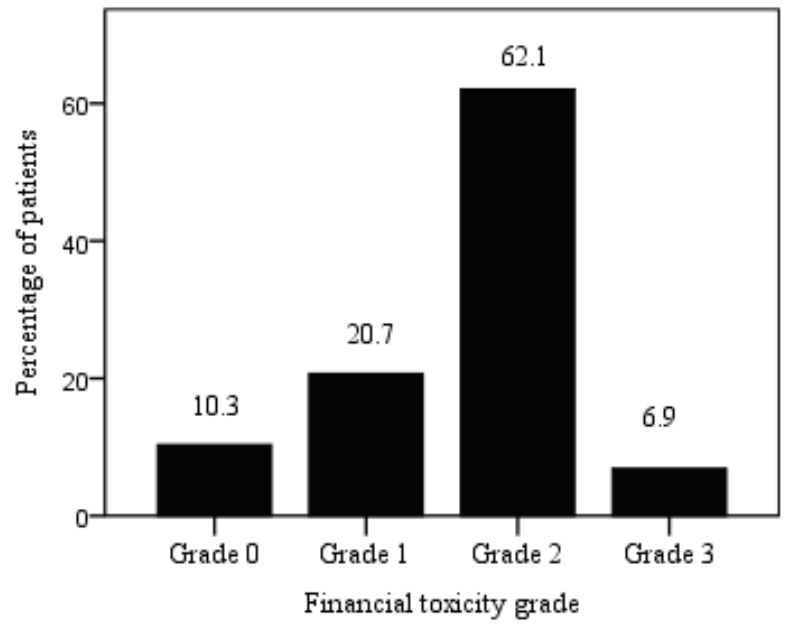

Figure 3. Patient distribution by FT grade; COST score $\geq 26$ (Grade 0), 14-25 (Grade 1), 1-13 (Grade 2) and 0 (Grade 3).

\section{Discussion}

A total of 29 head and neck cancer patients attending radiation oncology OPD on follow-up were included in this study. Almost $83 \%$ of the study participants were male and 62\% cases were cancers of lip and oral cavity. According to GLOBOCAN-2018, lip-oral cancers are second leading cause of incidence (10.4\%) and mortality (9.3\%) among cancer patients in India following breast cancer. Lip-oral cancers are the leading cause of incidence (16.1\%) and mortality (12.3\%) among males in India [32]. 
Table 6. Cost communication behaviour and cost coping strategies $(N=29)$.

\begin{tabular}{|l|l|}
\hline Cost discussion with radiation oncologist & $\mathbf{n}(\%)$ \\
\hline Yes & $26(89 \cdot 6 \%)$ \\
\hline No & $3(10 \cdot 4 \%)$ \\
\hline Cost coping strategies employed & \\
\hline Applied for financial assistance & $25(86 \%)$ \\
\hline Used savings & $16(55 \%)$ \\
\hline Borrowed from social nets & $20(69 \%)$ \\
\hline Borrowed money on interest & $9(31 \%)$ \\
\hline Sold assets & $6(21 \%)$ \\
\hline Skipped follow-up or recommended treatment/test & $2(7 \%)$ \\
\hline
\end{tabular}

All the patients (100\%) belonged to rural residences, $34 \%$ of the participants were not educated, $48 \%$ had only primary level education, $34.3 \%$ were manual labourers, $10 \%$ were unemployed, $13.8 \%$ were employed and others were farmers and housewives. Also $58.6 \%$ reported less than Rs. 50,000 annual household income, while 38\% had 0.5-1 lakh annual income. 93\% participants had no knowledge of health insurance and 62\% reported stopped working due to cancer. The sociodemographic data in this study correlates with the data from The Ministry of Rural Development, Government of India: Socio Economic and Caste Census (SECC) 2011 [33]. According to SECC, Bihar state has 89\% rural households, $44 \%$ illiteracy, $20 \%$ below primary level education, $54.8 \%$ landless households earning by manual labour, $3.8 \%$ households with salaried job income and 71\% households having less than Rs. 5000 monthly income [33].

The results of our pilot study show that internal consistency of COST measure was excellent with a Cronbach's a of 0.92 and no increase in Cronbach's a values was observed if any individual items were deleted, corroborating with the results of the original COST development study (Cronbach's $a=0.92$ ) [16]. The Cronbach's a coefficient was higher in this study as compared to validation studies in Japanese, Italian and Brazilian studies which reported a Cronbach's a of 0.87, 0.83 and 0.82, respectively [23-25].

Spearman's correlation test for all the items in the COST measure demonstrated that the items have a good correlation with each other. A significant positive correlation with large effect size was observed in 31 correlation combinations as depicted by $r_{\mathrm{s}}$ values. A total of $70 / 110$ correlation combinations were significant based on $p$-value indicating $63.6 \%$ significant correlation. These results were lower as compared to Brazilian version of COST which showed 78.2\% significant correlations on Spearman's correlation test [25]. However, this study showed higher number of large effect size correlations combinations (31) in all items as compared to Brazilian version which reported only three stronger correlation combinations in all items.

$\mathrm{KMO}$ and Bartlett's test demonstrated the sample adequacy and strength of the relationship between COST items were good supporting the factorial analysis. Again, these results were comparable with the original COST development study which reported a KMO of 0.9 [16]. The $\mathrm{KMO}$ value observed in this study (0.87) was higher as compared to the KMO values of Italian (0.82), and Brazilian (0.81) validation studies $[24,25]$. The suitability of data for EFA was also demonstrated using multivariate normality, factorability and multicollinearity analysis.

EFA was conducted for 11 COST items using parallel analysis for determining the number of factors to retain. Parallel analysis has already been discussed in results section and one factor with eigenvalue of 6.21 explaining $56.5 \%$ of the variance by non-rotated solution was identified. This result was consistent with the original COST development study which clearly identified one factor with eigenvalues of 5.68 explaining $89 \%$ of the variance on scree plot during factorability of the items [16]. COST validation studies conducted in Italy and Brazil reported a two-factor model; however, one factor model best represents the COST measure, and that factor was designated as FT [16, 24, 25]. The \%age variance explained was lower in this study as compared to the parent COST study (89\%) and Italian version (63\%) but higher than the Brazilian version (51.6\%) [16, 24, 25]. 
EFA showed that all the factor loadings in one factor model were $>0.3$ (range 0.35-0.97). Six items showed excellent loadings for Factor 1 , one item with very good loading, one with good loading and two items with acceptable loadings ( $>0.3)$ for Factor-1. These factor analysis loadings indicate the underlying construct can be considered as one factor domain as intended by the original study [16]. However, Chisquare goodness of fit test revealed the one factor model did not adequately depict the data mostly due to lower sample size but the results were acceptable and supporting the original COST development study as compared to Brazilian and Italian studies which reported two factor models.

The total COST score in this study indicated $62.1 \%$ patients suffered moderate impact, $20.7 \%$ mild and $6.9 \%$ experienced high impact FT. $69 \%$ of the patients responded not having money in savings or retirement to cover cancer care expenses and $72.4 \%$ felt that their illness has been a financial hardship to them and their family as well. Two studies conducted in Indian cancer patients revealed $76.5 \%$ and $84 \%$ cancer patients and households experienced catastrophic OOP expenditures [12, 34].

About $90 \%$ of the patients talked to attending oncologists regarding their financial hardships. Most patients were given information regarding financial assistance provided by Pradhan Mantri Jan Arogya Yojana and chief ministers medical assistance fund (Bihar) scheme both of which provide financial assistance to below poverty line households based on SECC-2011 data and 86\% patients in this study received one or other form of financial assistance for treatment related costs. Due to cancer care, $62 \%$ of patients stopped working and $20 \%$ reported reduction in work. Despite financial assistance, high OOP expenses in diagnostics, medications for RT side effects, travelling, food, lodging and loss of income forced patients to employ coping strategies to pay for cancer care. $7 \%$ skipped follow-ups, 55\% used their savings, $31 \%$ borrowed money on interest and $69 \%$ borrowed money from social nets. Rajpal et al [13] reported $40 \%$ of cancer patients use borrowings, sale of assets as coping strategies to pay for cancer treatment. As all the patients belonged to rural areas, majority complained that travelling from rural areas to radiotherapy centre, food and lodging expenses were high and difficult to pay adding to financial burden. A study conducted at AIIMS, New Delhi reported that about 59\% of the cancer care was spent on transportation, food and lodging during RT treatment [14].

To the authors' knowledge, this is the first study assessing the FT from the perspective of cancer patients in Indian health care system. FT and associated cost coping behaviour can prove detrimental particularly to the patients from lower socio-economic status.

In this study, the COST measure has demonstrated reliability and validity among head and neck cancer patients undergoing RT. However, the COST measure can prove to be a useful tool in measuring FT among other cancer subsites and treatment modalities including chemotherapy, surgery or multimodality treatments. COST measure will be useful in screening the patients at risk of FT and help in making better strategies and policies to alleviate the financial burden among cancer patients. Further studies are warranted for assessment of prevalence of FT among different cancer subsites in various cancer centres across India.

The limitation in this study is the small sample size. Based on the results of this study, we have initiated a prospective study of a larger sample size including other cancer subsites (breast cancer, abdominal cancer and other cancer patients) to further test the validation of COST for measuring FT and its association with HRQOL and other sociodemographic and clinical characteristics in cancer patients.

\section{Conclusion}

In conclusion, this pilot study demonstrated an excellent reliability and validity of COST for measuring FT among head and neck radiation oncology patients. Further studies are warranted in different cancer subsites across various cancer centres in India. The clinical implications of FT and feasibility of the COST measure among other cancer subsites and treatment modalities need to be evaluated.

\section{Acknowledgments}

The authors would like to express sincere gratitude to Director NIPER, Hajipur and Director MCSRC for their support throughout this work and the authors would like to thank all the staff members at the department of radiation therapy, MCSRC and all the patients who participated in this study. A special thanks to Dr. Munir for constant inspiration and proofreading the final manuscript. 


\section{Authors' contributions}

Mukhtar Ahmad Dar conceptualised and designed the study and contributed to literature search, data collection, data analysis and drafted the original manuscript. Richa Chauhan was study co-supervisor and contributed to patient recruitment, data collection, manuscript writing and resources necessary for this study. Krishna Kumar Sharma was the study supervisor and contributed in data analysis, review and editing the manuscript. Vinita Trivedi contributed to patient recruitment and manuscript editing and revisions. Sameer Dhingra and Krishna Murti have contributed to manuscript revisions, editing and proof-reading the final revised manuscript. The final version of the manuscript has been read and approved by all the authors for submission.

\section{Conflicts of interest}

The authors declare that they have no conflicts of interest.

\section{Funding}

This research did not receive any specific grant from funding agencies in the public, commercial or not for profit sectors.

\section{References}

1. World Health Organization (2018) Global Health Observatory (Geneva: World Health Organization) [https://gco.iarc.fr] Date accessed: $30 / 12 / 20$

2. Zafar SY, Peppercorn JM, and Schrag D, et al (2013) The financial toxicity of cancer treatment: a pilot study assessing out-of-pocket expenses and the insured cancer patient's experience Oncologist 18(4) 381-390 https://doi.org/10.1634/theoncologist.2012-0279 PMID: 23442307 PMCID: 3639525

3. Altice CK, Banegas MP, and Tucker-Seeley RD, et al (2017) Financial hardships experienced by cancer survivors: a systematic review JNCI 109(2) 1-17 https://doi.org/10.1093/jnci/djw205 PMID: 27754926

4. Zafar SY, McNeil RB, and Thomas CM, et al (2014) Population-based assessment of cancer survivors' financial burden and quality of life: a prospective cohort study J Oncol Pract 11(2) 145-150 https://doi.org/10.1200/JOP.2014.001542 PMID: 25515717 PMCID: 4371118

5. Delgado-Guay M, Ferrer J, and Rieber AG et al (2015) Financial distress and its associations with physical and emotional symptoms and quality of life among advanced cancer patients Oncologist 20(9) 1092-1098 https://doi.org/10.1634/theoncologist.2015-0026 PMID: 26205738 PMCID: 4571810

6. Ramsey SD, Bansal A, and Fedorenko CR et al (2016) Financial insolvency as a risk factor for early mortality among patients with cancer J Clin Oncol 34(9) 980-986 https://doi.org/10.1200/JCO.2015.64.6620 PMID: 26811521 PMCID: 4933128

7. Ramsey S, Blough D, and Kirchhoff A et al (2013) Washington State cancer patients found to be at greater risk for bankruptcy than people without a cancer diagnosis Health Aff 32(6)1143-1152 https://doi.org/10.1377/hlthaff.2012.1263 PMID: 23676531

8. Knight TG, Deal AM, and Dusetzina SB et al (2018) GR. Financial toxicity in adults with cancer: adverse outcomes and noncompliance J Oncol Pract 14(11) e665-e673 https://doi.org/10.1200/JOP.18.00120

9. Dusetzina SB, Winn AN, and Abel GA, et al (2014) Cost sharing and adherence to tyrosine kinase inhibitors for patients with chronic myeloid leukemia J Clin Oncol 32(4) 306-311 https://doi.org/10.1200/JCO.2013.52.9123 
10. Zullig LL, Peppercorn JM, Schrag D et al (2013) Financial distress, use of cost-coping strategies, and adherence to prescription medication among patients with cancer J Oncol Pract 9(6S) 60s-63s https://doi.org/10.1200/JOP.2013.000971 PMID: 29431038 PMCID: 3825170

11. Piette JD, Heisler M, and Wagner TH (2004) Cost-related medication underuse among chronically III adults: the treatments people forgo, how often, and who is at risk Am J Public Health 94(10) 1782-1787 https://doi.org/10.2105/AJPH.94.10.1782 PMID: 15451750 PMCID: 1448534

12. Basavaiah G, Rent PD, and Rent EG et al (2018) Financial impact of complex cancer surgery in India: a study of pancreatic cancer $J$ Glob Oncol 4 1-9 https://doi.org/10.1200/jgo.17.00151 PMID: 30241272 PMCID: 6223534

13. Rajpal S, Kumar A, and Joe W (2014) Economic burden of cancer in India: Evidence from cross-sectional nationally representative household survey PLoS One 13(2) 1-17 https://doi.org/10.1371/journal.pone.0193320

14. Mohanti BK (2011) Estimating the economic burden of cancer at a tertiary public hospital: a study at the All India Institute of Medical Sciences. Indian Statistical Institute, New Delhi, India 1-17 [https://www.isid.ac.in/ pu/dispapers/dp11-09.pdf] Date accessed: 03/01/21

15. Barwal VK, Thakur A, and Mazta SR, et al (2019) Out-of-Pocket expenditure for diagnosis of lung cancer: a significant pre-treatment financial burden-Study from a tertiary care cancer center in North India CHRISMED J Health Res 6(1) 18-22 https://doi.org/10.4103/ cjhr.cjhr_16_18

16. De Souza JA, Yap BJ, Hlubocky FJ et al (2014) The development of a financial toxicity patient-reported outcome in cancer: the COST measure Cancer 120(20) 3245-3453 https://doi.org/10.1002/cncr.28814 PMID: 24954526

17. De Souza JA, Yap BJ, and Wroblewski $\mathrm{K}$ et al (2017) Measuring financial toxicity as a clinically relevant patient-reported outcome: the validation of the Comprehensive Score for financial Toxicity (COST) Cancer 123(3) 476-484 https://doi.org/10.1002/cncr.30369 PMCID: 5298039

18. D'Rummo KA, Miller L, and TenNapel MJ, et al (2020) Assessing the financial toxicity of radiation oncology patients using the validated comprehensive score for financial toxicity as a patient-reported outcome Pract Radiat Oncol 10(5) e1-e8 https://doi.org/10.1016/j. prro.2019.10.005

19. Bouberhan S, Shea M, and Kennedy A, et al (2019) Financial toxicity in gynecologic oncology Gynecol Oncol 154(1) 8-12 https://doi. org/10.1016/j.ygyno.2019.04.003 PMID: 31053404 PMCID: 7001853

20. Huntington SF, Weiss BM, and Vogl DT, et al (2015) Financial toxicity in insured patients with multiple myeloma: a cross-sectional pilot study Lancet Haematol 2(10) e408-e416 https://doi.org/10.1016/S2352-3026(15)00151-9 PMID: 26686042

21. Hazell SZ, Fu W, Hu C, et al (2020) Financial toxicity in lung cancer: an assessment of magnitude, perception, and impact on quality of life Ann Oncol 31(1) 96-102 https://doi.org/10.1016/j.annonc.2019.10.006 PMID: 31912803

22. Allcott N, Dunham L, and Levy D, et al (2019) Financial burden amongst cancer patients treated with curative intent surgery alone $A m$ J Surg 218(3) 452-456 https://doi.org/10.1016/j.amjsurg.2019.01.033 PMID: 30771864 PMCID: 6743732

23. Honda K, Gyawali B, and Ando M, et al (2018) A prospective survey of comprehensive score for financial toxicity in Japanese cancer patients: report on a pilot study ecancer 12 1-8 https://doi.org/10.3332/ecancer.2018.847 PMID: 30079109

24. Ripamonti $\mathrm{Cl}$, Chiesi F, and Di Pede P, et al (2020) The validation of the Italian version of the Comprehensive Score for financial Toxicity (COST) Support Care Cancer 28 4477-4485 https://doi.org/10.1007/s00520-019-05286-y PMID: 31925533

25. De Alcantara Nogueira L, Koller FJ, and Marcondes L, et al (2020) Validation of the comprehensive score for financial toxicity for Brazilian culture ecancer 14 1-12 https://doi.org/10.3332/ecancer.2020.1158

26. Webster K, Cella D, and Yost K (2003) The functional assessment of chronic illness therapy (FACIT) measurement system: properties, applications, and interpretation Health Qual Life Outcomes 1(1) 1-7 https://doi.org/10.1186/1477-7525-1-79 
27. Williams B, Onsman A, Brown T (2010) Exploratory factor analysis: A five-step guide for novices Australas J Paramedicine 8(3) 1-13 https://doi.org/10.33151/ajp.8.3.93

28. Bartlett MS (1954) A note on multiplying factors for various chi square approximations J R Stat Soc 16(2) 296-298 [http://www.jstor. org/stable/2984057]

29. Cohen J (2013) Statistical Power Analysis for the Behavioural Sciences (Cambridge: Academic Press)

30. Çokluk Ö and Koçak D (2016) Using Horn's parallel analysis method in exploratory factor analysis for determining the number of factors Educ Sci Theory Pract 16(2) 537-551 https://doi.org/10.12738/estp.2016.2.0328

31. Tabachnick BG, Fidell LS, and Ullman JB (2007) Using Multivariate Statistics (Boston: Pearson)

32. Globocan India (2018) Population fact sheets p. 1-2 [https://gco.iarc.fr/today/data/factsheets/populations/356-india-fact-sheets.pdf] Date accessed: 25/12/20

33. The Ministry of Rural Development, Government of India (2011) Socio Economic and Caste Census 2011 [https://secc.gov.in/] Date accessed: 05/01/21

34. Jain M and Mukherjee K (2016) Economic burden of breast cancer to the households in Punjab, India Int J Med Public Health 6(1) 13-18 https://doi.org/10.4103/2230-8598.179754 


\section{Supplementary information}

\section{COST - FACIT (Version 2)}

Below is a list of statements that other people with your illness have said are important. Please circle or mark one number per line to indicate your response as it applies to the past 7 days.

\begin{tabular}{|c|c|c|c|c|c|c|}
\hline & & $\begin{array}{l}\text { Not } \\
\text { at all }\end{array}$ & $\begin{array}{c}\text { A little } \\
\text { bit }\end{array}$ & $\begin{array}{c}\text { Some- } \\
\text { what }\end{array}$ & $\begin{array}{l}\text { Quite } \\
\text { a bit }\end{array}$ & $\begin{array}{l}\text { Very } \\
\text { much }\end{array}$ \\
\hline $\mathrm{FT}$ & 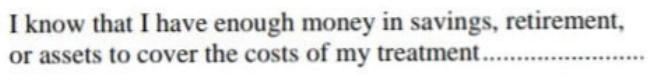 & 0 & 1 & 2 & 3 & 4 \\
\hline $\mathrm{FT}$ & 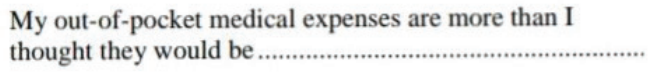 & 0 & 1 & 2 & 3 & 4 \\
\hline $\mathrm{FT3}$ & 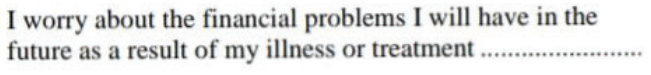 & 0 & 1 & 2 & 3 & 4 \\
\hline $\mathrm{Fr}$ & $\begin{array}{l}\text { I feel I have no choice about the amount of money I } \\
\text { spend on care }\end{array}$ & 0 & 1 & 2 & 3 & 4 \\
\hline FTS & 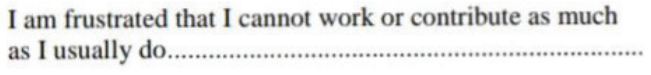 & 0 & 1 & 2 & 3 & 4 \\
\hline FT6 & I am satisfied with my current financial situation ................. & 0 & 1 & 2 & 3 & 4 \\
\hline m & 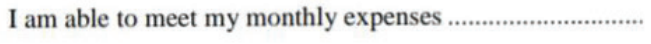 & 0 & 1 & 2 & 3 & 4 \\
\hline $\mathrm{Frs}$ & 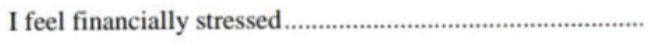 & 0 & 1 & 2 & 3 & 4 \\
\hline $\mathbf{p r g}$ & 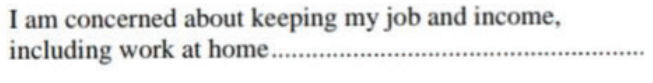 & 0 & 1 & 2 & 3 & 4 \\
\hline Frio & $\begin{array}{l}\text { My cancer or treatment has reduced my satisfaction with } \\
\text { my present financial situation }\end{array}$ & 0 & 1 & 2 & 3 & 4 \\
\hline FriI & 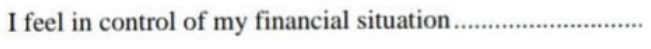 & 0 & 1 & 2 & 3 & 4 \\
\hline $\mathrm{FT12}$ & $\begin{array}{l}\text { My illness has been a financial hardship to my family } \\
\text { and me }\end{array}$ & 0 & 1 & 2 & 3 & 4 \\
\hline
\end{tabular}

Supplementary Figure 1. COST-FACIT-Version 2. 